\title{
RANCANG BANGUN ALAT MONITORING KETIDAKSEIMBANGAN BEBAN PADA JARINGAN TEGANGAN MENENGAH
}

\author{
Osea Zebua*, Angga Hidson Setiawan, Noer Soedjarwanto, Jemi Anggara, Abdul Haris \\ Jurusan Teknik Elektro, Universitas Lampung \\ *Corresponding author, e-mail : oseaz2009@gmail.com
}

\begin{abstract}
Abstrak - Ketidakseimbangan beban merupakan gangguan yang dapat merusak transformator daya di jaringan tegangan menengah. Ketidakseimbangan beban atau ketidakseimbangan arus yang besar menyebabkan pemanasan pada belitan transformator dan menyebabkan kerusakan fatal bila berlangsung pada waktu yang lama. Salah satu cara untuk mencegah kerusakan ini adalah dengan memonitoring persentase ketidakseimbangan beban atau ketidakseimbangan arus di jaringan tegangan menengah. Makalah ini menyajikan perancangan dan pembuatan alat monitoring ketidakseimbangan beban pada jaringan tegangan menengah. Mikrokontroler Arduino digunakan sebagai pengendali utama. Sensor arus dan sensor tegangan digunakan untuk memperoleh data arus dan tegangan setiap saat. Hasil monitoring ketidakseimbangan beban yang melebihi nilai yang sudah ditentukan dikirim ke sistem peringatan dan handphone. Hasil pengujian pada sisi sekunder transformator daya menunjukkan bahwa peralatan dapat memonitoring ketidakseimbangan beban (arus) dengan perbedaan maksimum 0,17\%, ketidakseimbangan tegangan dengan perbedaan maksimum $0,033 \%$ dan arus netral dengan perbedaan maksimum 3,29A dibandingkan dengan nilai-nilai sebenarnya. Alat monitoring juga mampu mengirimkan data arus ke sistem peringatan bunyi dan ke handphone bila persentase ketidakseimbangan beban (arus) melebihi nilai yang sudah ditentukan, yakni $30 \%$.
\end{abstract}

Kata Kunci : ketidakseimbangan beban, monitoring, jaringan tegangan menengah, transformator daya

\begin{abstract}
Load unbalance is a fault that can damage power transformers in medium voltage networks. The larger load or current unbalance cause heating at the transformer winding and can cause fatal damage if it occurs in a long time. One way to prevent this damage is by monitoring the percentage of load unbalance or current unbalance in medium voltage network. This paper presents the design of load unbalance monitoring equipment on medium voltage networks. Arduino microcontroller is used as the main controller. Current sensors and voltage sensors are used to obtain the data of current and voltage at any time. The load unbalance monitoring result that exceeds the setting value is sent to a warning systems and mobile phones. The test results on the secondary side of the power transformer showed that the equipment can monitor load (current) unbalance with a maximum difference of $0.17 \%$, voltage unbalance with maximum difference of $0.033 \%$ and neutral current with maximum difference of $3.29 \mathrm{~A}$ compared to the actual values. The monitoring equipment is also capable of sending data to sound warning system and to the mobile phone when the percentage of load (current) unbalance exceeds the setting value, i.e. $30 \%$.
\end{abstract}

Keywords : load unbalance, monitoring, medium voltage network, power transformer

Copyright $\odot 2016$ JNTE. All rights reserved

\section{PENDAHULUAN}

Energi listrik merupakan energi yang sangat dibutuhkan oleh manusia pada saat sekarang ini. Pendistribusian energi listrik dilakukan dengan berbagai peralatan listrik termasuk di antaranya transformator, kabel dan berbagai peralatan switching yang terdapat di gardu induk, gardu distribusi dan gardu hubung. Pada jaringan tegangan menengah, transformator daya memegang peranan penting dalam pendistribusian tenaga listrik. Oleh karena banyaknya gangguan yang terjadi pada operasi sistem tenaga listrik setiap saat, maka biasanya peralatan-peralatan utama termasuk transformator daya mempunyai peralatan proteksi terhadap gangguan.

Gangguan-gangguan internal dan eksternal pada transformator daya biasanya telah diproteksi dengan berbagai peralatan proteksi yang terpasang pada transformator dan di jaringan tegangan menengah. Salah satu jenis gangguan yang biasanya di luar zona proteksi dari peralatan-peralatan proteksi adalah 
ketidakseimbangan beban. Beban-beban yang terhubung pada setiap fasa dari jaringan tegangan menengah biasanya tidak sama besarnya setiap saat, sehingga tegangan dan arus pada setiap fasa berbeda.

Bila perbedaan arus yang mengalir sangat besar, maka akan mengalir arus yang cukup besar pada kawat netral, bila menggunakan sistem empat kawat atau akan mengalir arus pada kawat tanah (ground) bila menggunakan sistem tiga kawat yang ditanahkan. Hal ini mengakibatkan transformator daya mengalami pemanasan lebih dan kemudian dapat memicu terjadinya kenaikan temperatur pada sistem isolasi di transformator. Selanjutnya hal ini akan memicu kegagalan isolasi transformator daya dan biasanya kegagalan isolasi sifatnya lama baru diketahui. Bila isolasi gagal untuk memproteksi konduktor maka dapat menyebabkan kerusakan transformator daya dan tentu mengganggu kontinuitas pendistribusian daya listrik. Kejadian ini biasanya tidak dapat dapat dipantau dan kadang-kadang disebut dengan gangguan yang tidak dapat diperkirakan [1].

Oleh karena itu peralatan yang mendeteksi ketidakseimbangan beban yang besar sangat dibutuhkan untuk memastikan bahwa transformator dapat bekerja secara kontinyu dalam pendistribusian daya pada jaringan tegangan menengah. Hal ini dibutuhkan oleh operator yang bekerja di gardu induk untuk mengambil langkah bila ketidakseimbangan beban yang besar terjadi dalam waktu yang lama.

Peralatan deteksi ketidakseimbangan beban yang besar pada jaringan tegangan menengah sangat dibutuhkan untuk mendeteksi sekaligus memonitoring besar persentase ketidakseimbangan yang terjadi pada jaringan tegangan menengah atau pada sisi sekunder transformator daya.

Makalah ini menyajikan desain dan pembuatan peralatan monitoring ketidakseimbangan beban berbasis mikrokontroler yang dapat memonitoring persentase ketidakseimbangan beban dan mengirimkan data bila terjadi persentase ketidakseimbangan beban yang melebihi nilai yang ditentukan ke sistem peringatan dengan bunyi dan pesan singkat ke handphone.

\section{TINJAUAN PUSTAKA}

\subsection{Ketidakseimbangan Beban}

Beban-beban yang terhubung pada setiap fasa pada setiap waktu di jaringan tegangan menengah selalu tidak sama besarnya. Ketidakseimbangan beban ini akan mengakibatkan tegangan fasa ke fasa dan arus yang mengalir pada setiap fasa juga tidak sama besarnya.

Ketidakseimbangan beban biasanya dinyatakan dengan ketidakseimbangan arus. Besar persentase ketidakseimbangan beban atau ketidakseimbangan arus, $U_{I}$ dinyatakan dengan [2]:

$$
U_{I}=\frac{\text { Deviasi arus fasa }}{\text { Nilai rata }- \text { rata arus fasa }} \times 100 \%
$$

atau bila dinyatakan dalam nilai arus fasa, maka:

$U_{I}=\frac{\left|I_{R}-I_{\text {avg }}\right|+\left|I_{S}-I_{\text {avg }}\right|+\left|I_{T}-I_{\text {avg }}\right|}{I_{\text {avg }}} \times 100 \%$

dimana $I_{R}, I_{S}, I_{T}$ masing-masing adalah nilai rms dari arus fasa R, fasa $\mathrm{S}$ dan fasa T, dan $I_{\text {avg }}$ adalah nilai arus rata-rata yang besarnya:

$$
I_{\text {avg }}=\frac{I_{R}+I_{S}+I_{T}}{3}
$$

Persamaan (2) juga dapat dinyatakan dengan:

$$
U_{I}=\frac{|a-1|+|b-1|+|c-1|}{3} \times 100 \%
$$

dimana,

$a=\frac{I_{R}}{I_{\text {avg }}}$

$b=\frac{I_{S}}{I_{\text {avg }}}$

$c=\frac{I_{T}}{I_{\text {avg }}}$

Koefisien a, b, dan c masing-masing menyatakan perbandingan nilai arus fasa $\mathrm{R}$, arus fasa $\mathrm{S}$ dan arus fasa $\mathrm{T}$ terhadap nilai arus fasa rata-rata. Pada kondisi seimbang, nilai arus ratarata sama dengan nilai arus setiap fasa dan besarnya koefisien $\mathrm{a}, \mathrm{b}$ dan $\mathrm{c}$ adalah 1 .

Besar persentase ketidakseimbangan tegangan yang terjadi pada saat 
ketidakseimbangan beban dinyatakan dengan:

$U_{V}=\frac{\text { Deviasi tegangan fasa ke fasa }}{\text { Nilai rata - rata tegangan fasa ke fasa }} \times 100 \%$

Bila dinyatakan dalam tegangan fasa ke fasa (tegangan line), maka:

$U_{V}=\frac{\left|V_{R S}-V_{\text {avg }}\right|+\left|V_{S T}-V_{\text {avg }}\right|+\left|V_{T R}-V_{\text {avg }}\right|}{V_{\text {avg }}} \times 100 \%$

dimana $V_{R S}, V_{S T}, V_{T R}$ masing-masing adalah tegangan antara fasa $R$ dan fasa $S$, antara fasa $S$ dan fasa $\mathrm{T}$ dan antara fasa $\mathrm{T}$ dan fasa $\mathrm{R}$ dan $V_{a v g}$ adalah tegangan fasa ke fasa rata-rata yang besarnya:

$$
V_{\text {avg }}=\frac{V_{R S}+V_{S T}+V_{T S}}{3}
$$
dengan:

Persamaan (9) juga dapat dinyatakan

$$
U_{V}=\frac{|d-1|+|e-1|+|f-1|}{3} \times 100 \%
$$

dimana,

$$
\begin{aligned}
& d=\frac{V_{R S}}{V_{a v g}} \\
& e=\frac{V_{S T}}{V_{a v g}} \\
& f=\frac{V_{T R}}{V_{a v g}}
\end{aligned}
$$

koefisien $\mathrm{d}$, e dan $\mathrm{f}$ masing-masing menyatakan perbandingan tegangan fasa $R$, fasa $S$ dan fasa $T$ terhadap tegangan rata-rata.

Nilai maksimum persentase ketidakseimbangan tegangan pada jaringan tegangan menengah yang diperbolehkan adalah $2 \%[3,4]$. Tidak ada standar nilai maksimum persentase ketidakseimbangan arus yang dapat menyebabkan ketidakseimbangan tegangan melebihi 2\%, sehingga nilai ini biasanya ditentukan secara tersendiri.

Pada transformator daya dengan hubungan belitan segitiga-bintang dengan netral (Dyn) atau bintang-bintang dengan netral (YnYn) biasanya mempunyai konduktor netral terhubung dengan tanah (ground) melalui tahanan pentanahan.
Ketidakseimbangan beban mengakibatkan mengalirnya arus pada konduktor netral $\left(I_{N}\right)[5]$, yang besarnya:

$$
I_{N}=I_{a v g} \times\left(a-\frac{(b+c)}{2}+j \frac{(c-b)}{2} \sqrt{3}\right)
$$

\subsection{Mikrokontroler Arduino}

Mikrokontroler Arduino adalah suatu prosesor kecil yang mempunyai memori untuk pemrograman dan dilengkapi dengan pin-pin masukan dan keluaran serta fitur-fitur lainnya. Pengendalian dilakukan dengan pemrograman yang ditulis pada EEPROM.

Mikrokontroler Arduino berbentuk papan (board) memiliki 14 pin digital masukan dan keluaran (dimana 6 pin dapat digunakan sebagai keluaran PWM), 6 pin analog (ADC), $16 \mathrm{MHz}$ osilator kristal, tombol reset. Suplai daya untuk mengaktifkan mikrokontroler Arduino ini dapat diperoleh dari sumber daya arus searah seperti baterai, power bank ataupun hasil penyearahan sumber daya arus bolak-balik (AC).

Mikrokontroler Arduino telah digunakan untuk berbagai kebutuhan pengendalian dan automatisasi [6].

\section{METODOLOGI PENELITIAN}

\subsection{Perancangan Alat}

Desain peralatan monitoring ketidakseimbangan beban pada jaringan tegangan menengah dijelaskan dengan blok diagram seperti ditunjukkan pada Gambar 1.

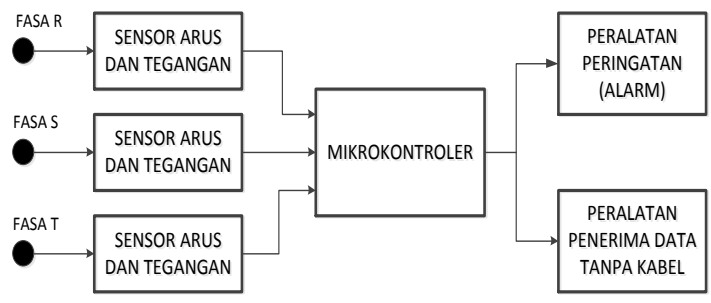

Gambar 1. Blok Diagram Perancangan Alat

Nilai arus dan tegangan setiap fasa diperoleh dengan menggunakan sensor arus dan sensor tegangan. Data arus dan tegangan digunakan untuk menghitung persentase ketidakseimbangan beban (ketidakseimbangan arus), persentase ketidakseimbangan tegangan dan arus pada konduktor netral. Data persentase ketidakseimbangan beban akan dikirimkan ke 
peralatan peringatan yang menggunakan alarm dan peralatan penerima data tanpa kabel yakni handphone, bila persentase ketidakseimbangan melampaui nilai yang sudah ditetapkan.

\subsection{Pembuatan Alat}

Peralatan-peralatan utama yang digunakan pada pembuatan alat monitoring ketidakseimbangan beban untuk jaringan tegangan menengah ini antara lain sensor arus, sensor tegangan, mikrokontroler Arduino, buzzer, GSM shield dan LCD (Liquid Crystal Device).

Sensor arus yang digunakan adalah sensor arus SCT 013-030. Sensor arus ini hanya dapat bekerja untuk kabel dengan arus satu arah dan dapat bekerja pada arus masukan sampai 30A. Rangkaian sensor arus untuk pembacaan arus setiap fasa ditunjukkan pada Gambar 2.

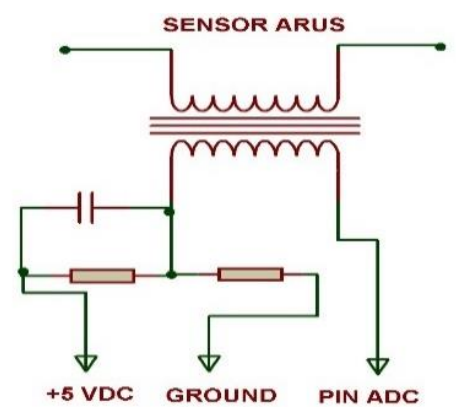

Gambar 2. Rangkaian Sensor Arus

Sensor tegangan yang digunakan adalah sensor ZMPT107 dengan tegangan masukan 0$1000 \mathrm{~V}$ dan tegangan keluaran $0-5 \mathrm{~V}$. bekerja pada arus $0-3 \mathrm{~mA}$. Rangkaian sensor tegangan yang terhubung dengan mikrokontroler Arduino ditunjukkan pada Gambar 3.

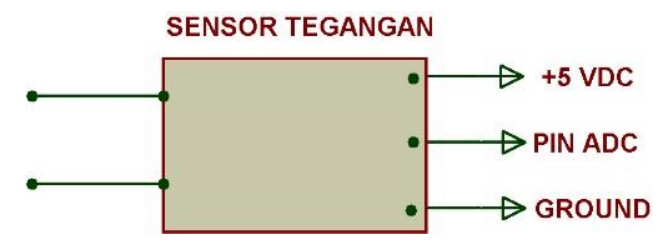

Gambar 3. Rangkaian Sensor Tegangan

Mikrokontroler yang digunakan adalah mikrokontroler Arduino Uno berbasis mikrokontroler ATMega328. Pin-pin analog sebanyak enam pin dihubungkan dengan keluaran dari sensor arus dan sensor tegangan. Sementara pin-pin digital keluaran digunakan untuk mengirimkan data ke sistem peringatan, pengiriman data ke handphone dan tampilan ke LCD, seperti ditunjukkan pada Gambar 4.

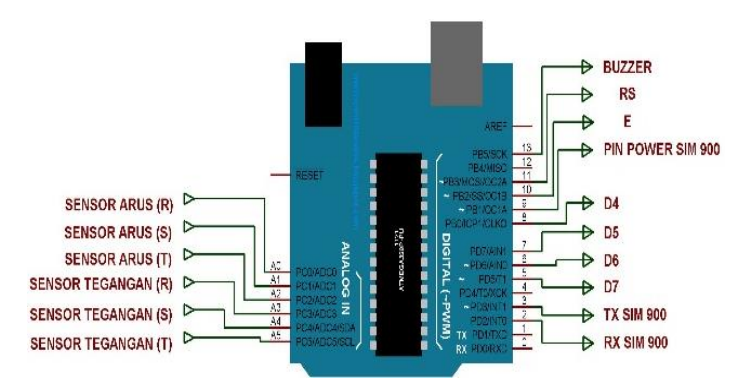

Gambar 4. Rangkaian Mikrokontroler

Buzzer digunakan untuk sistem peringatan (alarm) bila terdapat persen ketidakseimbangan arus dan tegangan serta arus netral yang melebihi nilai yang sudah ditentukan. Terminal buzzer dihubungkan langsung ke pin keluaran digital dari mikrokontroler Arduino tanpa menambahkan rangkaian tambahan disebabkan buzzer yang digunakan memakai daya yang kecil, seperti ditunjukkan pada Gambar 5.

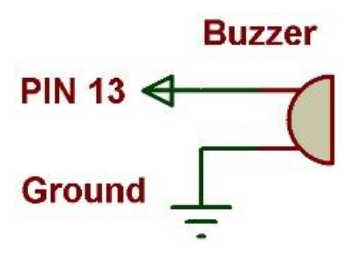

Gambar 5. Rangkaian Buzzer

GSM shield digunakan untuk mengirimkan data berupa pesan singkat (short message) ke handphone bila terdapat persentase ketidakseimbangan yang melebihi nilai yang ditentukan. GSM shield yang digunakan adalah modul IcomSat v1.1-SIM900. Data yang dikirim adalah data arus setiap fasa dan arus netral. Rangkaian sederhana dari GSM shield yang terhubung dengan mikrokontroler ditunjukkan pada Gambar 6.

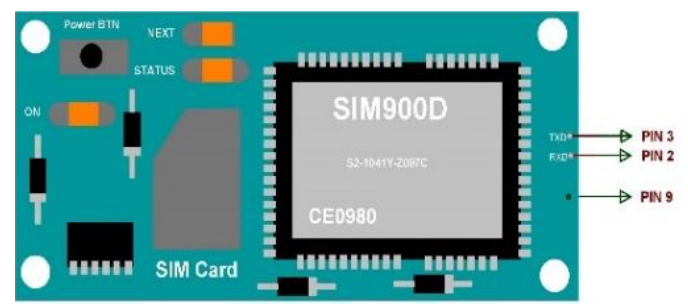

Gambar 6. Rangkaian GSM Shield 
LCD digunakan untuk menampilkan data dan rangkaiannya ditunjukkan pada Gambar 7.

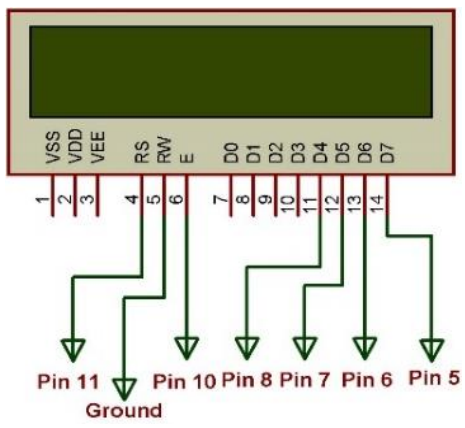

Gambar 7. Rangkaian LCD

\subsection{Perancangan Perangkat Lunak}

Perangkat lunak (program komputer) ditulis dengan menggunakan bahasa pemrograman $\mathrm{C}$. Perancangan perangkat lunak disesuaikan dengan bagan alir pemrograman yang ditunjukkan pada Gambar 8. Nilai seting untuk persentase ketidakseimbangan arus adalah sebesar $30 \%$, nilai seting untuk persentase ketidakseimbangan tegangan adalah $2 \%$ dan nilai seting arus netral adalah 60A [7].

Penulisan program ke mikrokontroler Arduino dilakukan dengan menggunakan perangkat lunak Arduino IDE.

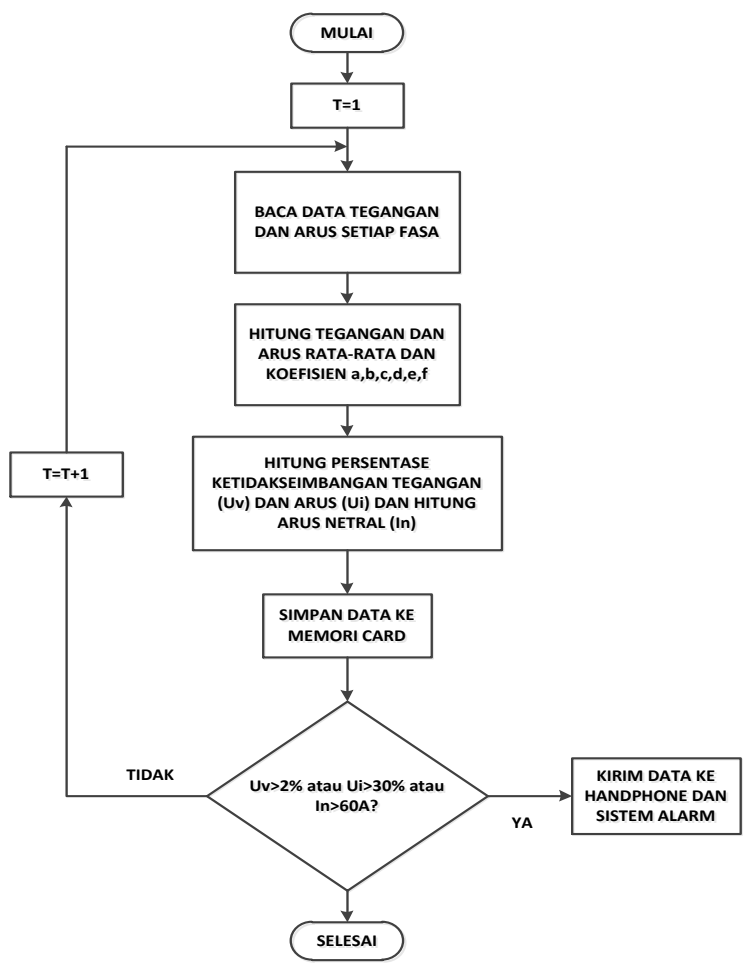

Gambar 8. Bagan Alir Pemrograman

\subsection{Pengujian}

Pengujian peralatan dilakukan dengan menggunakan simulasi rangkaian tiga fasa dengan rangkaian yang terhubung dengan lampu untuk melihat efektifitas peralatan.

Pengujian juga dilakukan secara langsung di jaringan tegangan menengah dengan menempatkan peralatan pada kubikel di ruang kontrol gardu induk New Tarahan, Lampung. Pengukuran arus dan tegangan pada kubikel merepresentasikan pengukuran arus dan tegangan pada sisi sekunder transformator daya. Spesifikasi transformator daya adalah 30 MVA, $150 \mathrm{kV} / 20 \mathrm{kV}, \quad 115 \mathrm{~A} / 492-866 \mathrm{~A}$ dengan hubungan belitan Ynyn0d5. Sisi sekunder transformator daya titik netralnya dihubungkan ke tanah melalui resistansi pentanahan $40 \mathrm{ohm}$ seperti ditunjukkan pada Gambar 9.

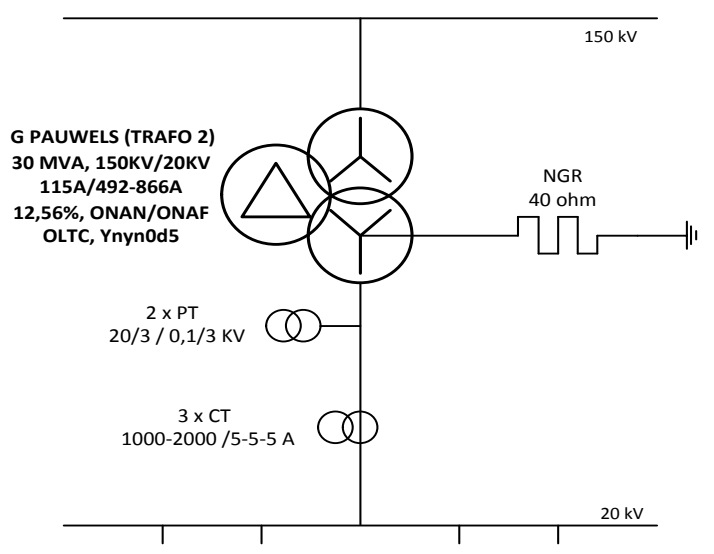

Gambar 9. Diagram Rangkaian Transformator Daya

\section{HASIL DAN PEMBAHASAN}

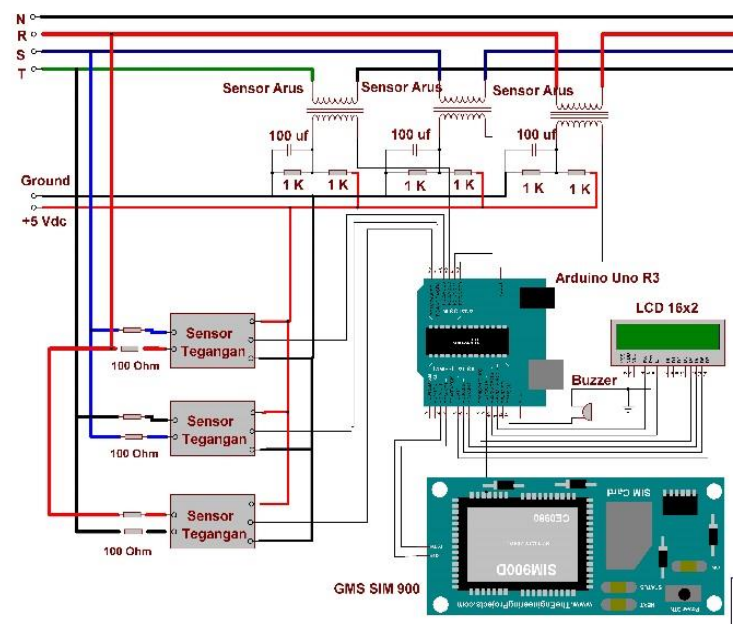

Gambar 10. Diagram Skema Rangkaian Alat 
Diagram skematik rangkaian alat monitoring ketidakseimbangan beban ditunjukkan pada Gambar 10 dan bentuk fisik alat monitoring ditunjukkan pada Gambar 11.

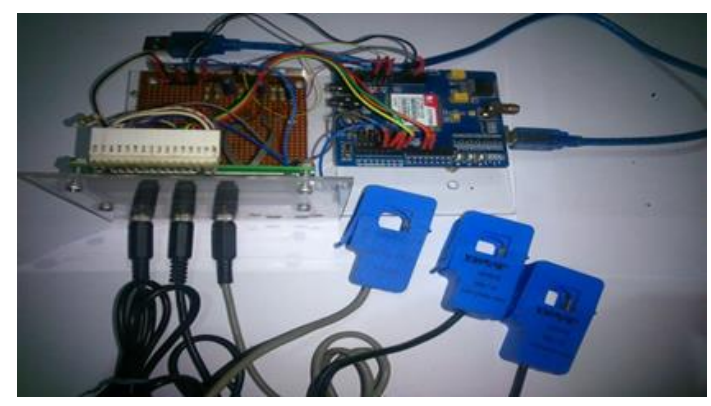

Gambar 11. Alat Monitoring Ketidakseimbangan Beban

\subsection{Hasil Pengujian}

Pengujian dilakukan dengan menggunakan rangkaian tiga fasa seperti ditunjukkan pada Gambar 12.

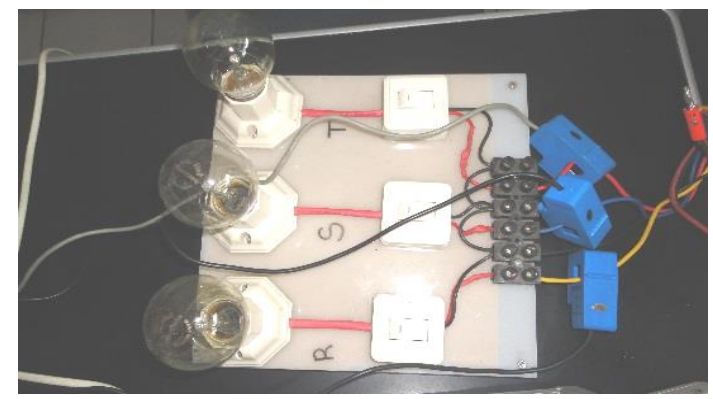

Gambar 12. Rangkaian Pengujian dengan Beban Lampu

Setiap fasa dihubungkan dengan beban lampu pijar dan pengujian dilakukan dengan menyalakan dan mematikan lampu secara bergantian serta mengganti lampu dengan daya yang berbeda. Hasil pengujian ditunjukkan pada Tabel 1.

Tabel 1. Hasil Pengujian Dengan Beban Lampu

\begin{tabular}{|c|c|c|c|c|c|c|c|c|c|}
\hline \multirow{2}{*}{ No. } & \multicolumn{3}{|c|}{$\begin{array}{c}\text { Beban Fasa } \\
\text { (W) }\end{array}$} & \multicolumn{3}{c|}{$\begin{array}{c}\text { Arus Fasa } \\
(\mathrm{A})\end{array}$} & \multicolumn{3}{c|}{$\begin{array}{c}\text { Tegangan Fasa } \\
\text { ke Fasa (V) }\end{array}$} \\
\cline { 2 - 11 } & $\mathrm{R}$ & $\mathrm{S}$ & $\mathrm{T}$ & $\mathrm{R}$ & $\mathrm{S}$ & $\mathrm{T}$ & $\mathrm{R}-\mathrm{S}$ & S-T & T-R \\
\hline 1 & 100 & 100 & 100 & 0,42 & 0,42 & 0,42 & 380 & 380 & 380 \\
\hline 2 & 60 & 100 & 100 & 0,26 & 0,42 & 0,42 & 380 & 380 & 380 \\
\hline 3 & 0 & 60 & 100 & 0 & 0,26 & 0,42 & 379 & 380 & 380 \\
\hline 4 & 60 & 0 & 100 & 0,26 & 0 & 0,42 & 380 & 379 & 380 \\
\hline 5 & 100 & 60 & 0 & 0,42 & 0,26 & 0 & 379 & 380 & 380 \\
\hline
\end{tabular}

Persentase ketidakseimbangan beban (ketidakseimbangan arus), ketidakseimbangan tegangan dan arus netral berdasarkan hasil perhitungan dan pengujian ditunjukkan pada Tabel 2.

Tabel 2. Perbandingan Persentase

Ketidakseimbangan dan Arus Netral

\begin{tabular}{|c|c|c|c|c|c|}
\hline \multirow{2}{*}{ No. } & \multicolumn{2}{|c|}{$\begin{array}{c}\text { Ketidakseimbangan } \\
\text { Beban (Arus) }(\%)\end{array}$} & \multicolumn{2}{c|}{$\begin{array}{c}\text { Ketidakseimbangan } \\
\text { Tegangan }(\%)\end{array}$} & $\begin{array}{c}\text { Arus } \\
\text { Netral }\end{array}$ \\
\cline { 2 - 6 } & $\begin{array}{c}\text { Hasil } \\
\text { Pengukuran }\end{array}$ & $\begin{array}{c}\text { Hasil } \\
\text { Perhitungan }\end{array}$ & $\begin{array}{c}\text { Hasil } \\
\text { Pengukuran }\end{array}$ & $\begin{array}{c}\text { Hasil } \\
\text { Perhitungan }\end{array}$ & $\begin{array}{c}\text { Hasil } \\
\text { Perhitungan }\end{array}$ \\
\hline 1 & 0 & 0 & 0 & 0 & 0 \\
\hline 2 & 19,4 & 19,39 & 0 & 0 & 0,16 \\
\hline 3 & 66,7 & 66,67 & 0,12 & 0,12 & 0,367 \\
\hline 4 & 66,7 & 66,67 & 0,12 & 0,12 & 0,367 \\
\hline 5 & 66,7 & 66,67 & 0,12 & 0,12 & 0,367 \\
\hline
\end{tabular}

Tampilan pada handphone pada pengujian dengan beban lampu yang melebihi persentase ketidakseimbangan arus ditunjukkan pada Gambar 13.

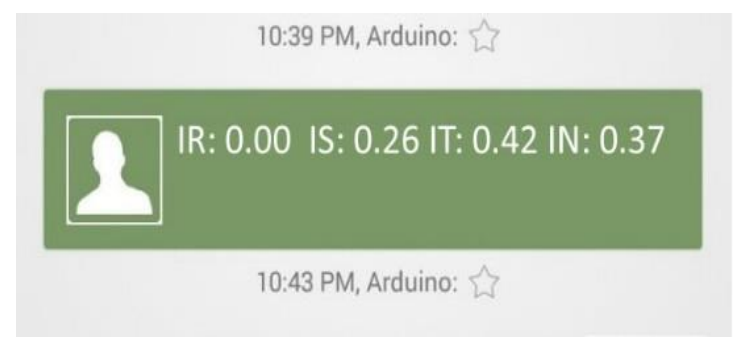

Gambar 13. Tampilan Data di Handphone

Pengiriman data arus fasa dan arus netral ke handphone memerlukan waktu tertentu, pada Gambar 8 lamanya pengiriman data adalah sekitar 4 menit. Lamanya waktu pengiriman data dipengaruhi oleh kekuatan sinyal dari jaringan telekomunikasi di tempat pengujian.

Pengujian juga dilakukan pada sisi sekunder transformator daya dengan mengambil titik pengukuran pada kubikel di ruang kontrol gardu induk New Tarahan, Lampung. Data tegangan fasa, arus fasa dan arus pada konduktor netral pada salah satu penyulang yang disuplai oleh transformator daya dengan hubungan belitan YnYn diambil setiap 1 menit selama 1 jam. Proses pengambilan data ditunjukkan pada Gambar 14 dan hasil pengujian pengukuran arus dengan alat yang dibuat dan alat ukur milik PLN ditunjukkan pada Gambar 15. 


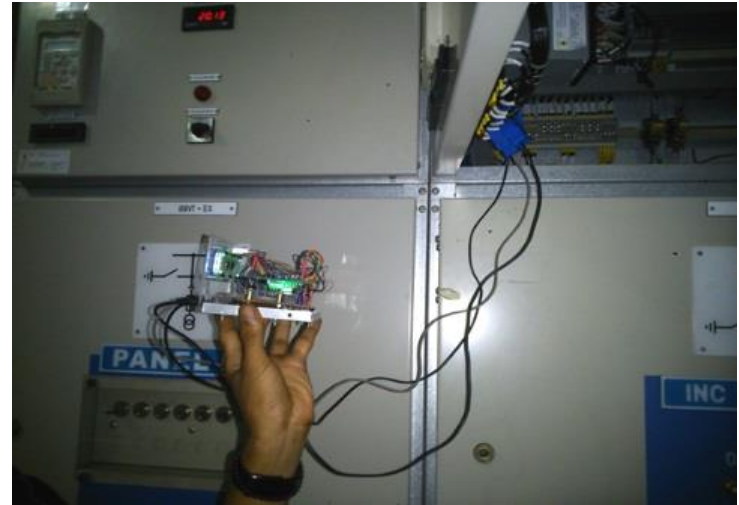

Gambar 14. Pengujian Pada Kubikel

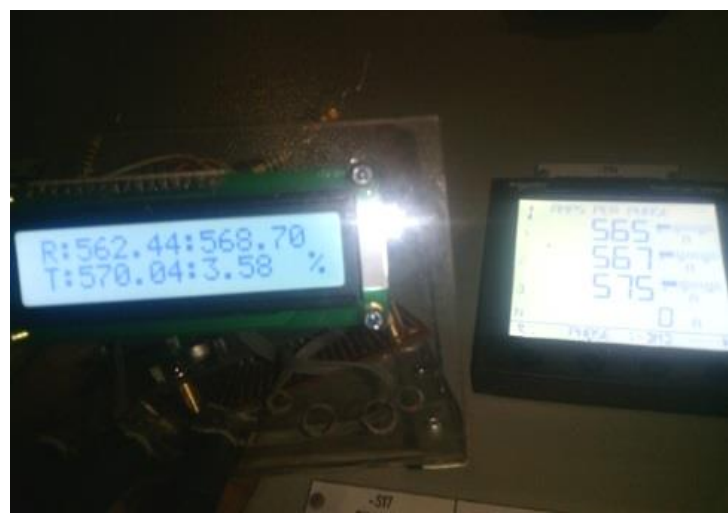

Gambar 15. Hasil Pengujian Pengukuran Arus

Pengujian untuk mengukur arus dan tegangan baik dengan menggunakan alat hasil rancangan dan pengukuran menggunakan alat ukur yang dimiliki oleh PLN mulai dilakukan pada malam hari antara pukul 20.35 sampai pukul 21.35. Perbandingan antara arus setiap fasa hasil pengukuran menggunakan alat monitoring dan alat ukur PLN ditunjukkan pada Gambar 16, 17 dan 18.

Hasil perhitungan arus fasa rata-rata yang diperoleh dari pengukuran dengan menggunakan alat monitoring dan alat ukur milik PLN ditunjukkan pada Gambar 19.

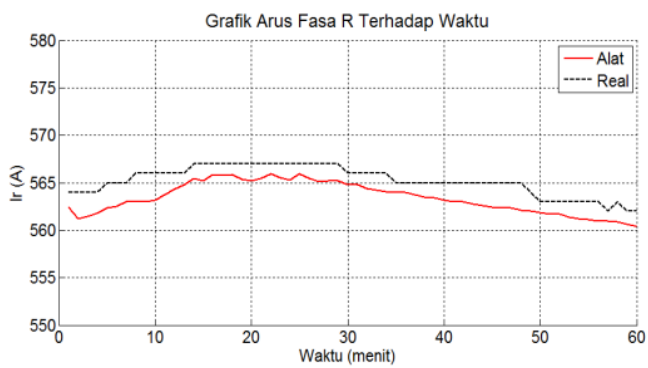

Gambar 16. Hasil Pengukuran Arus Fasa R

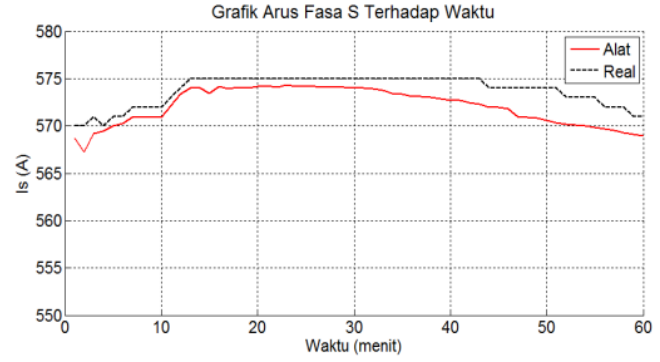

Gambar 17. Hasil Pengukuran Arus Fasa S

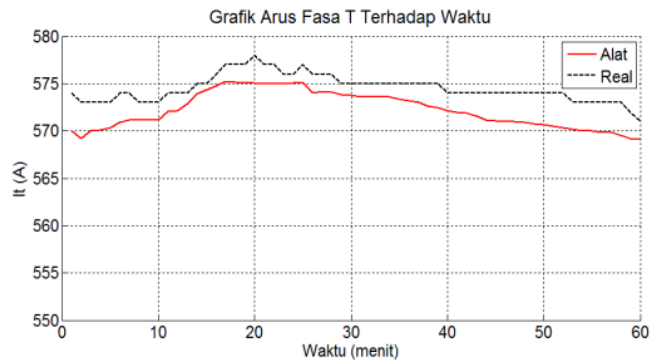

Gambar 18. Hasil Pengukuran Arus Fasa T

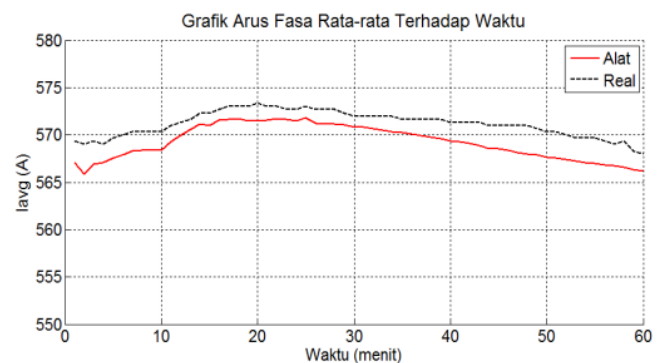

Gambar 19. Hasil Perhitungan Arus Fasa Rata-rata

Hasil perhitungan arus netral dengan menggunakan alat monitoring dan hasil pengukuran dengan menggunakan alat ukur PLN ditunjukkan pada Gambar 20.

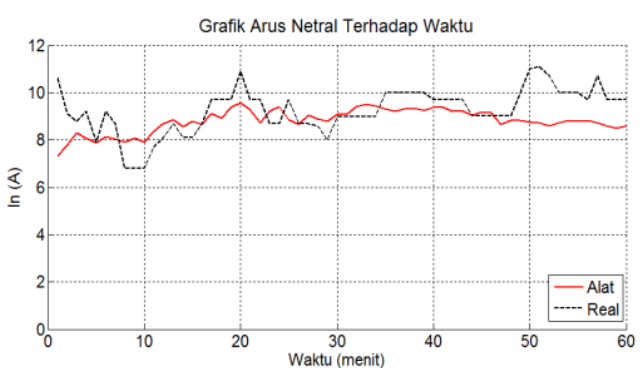

Gambar 20. Perbandingan Arus Netral

Hasil perhitungan persentase ketidakseimbangan beban (arus) dengan menggunakan alat monitoring dan alat ukur PLN ditunjukkan pada Gambar 21. 


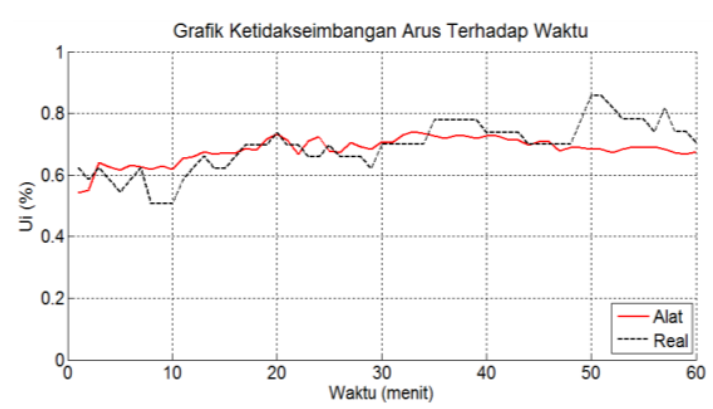

Gambar 21. Persentase Ketidakseimbangan Beban (Arus)

Hasil pengukuran arus fasa dan perhitungan arus netral dan persentase ketidakseimbangan arus dengan menggunakan alat yang dibuat memberikan hasil berbeda dengan hasil pengukuran dengan menggunakan alat ukur milik PLN. Perbedaan maksimum selama pengukuran arus fasa adalah sebesar 3,96A sehingga juga mempengaruhi perbedaan persentase ketidakseimbangan arus dan perbedaan arus netral. Hal ini kemungkinan disebabkan adanya induksi antara kabel telanjang yang menghubungkan bagian-bagian pada alat yang letaknya sangat berdekatan.

Selama pengujian dilakukan tidak ada data yang dikirimkan ke sistem peringatan dan ke handphone, hal ini disebabkan persentase ketidakseimbangan arus yang diperoleh tidak melebihi $30 \%$.

Perbedaan maksimum arus netral yang dihitung oleh alat dengan arus netral yang diukur oleh alat ukur milik PLN adalah 3,29A. Perbedaan persentase ketidakseimbangan arus maksimum yang diperoleh adalah $0,17 \%$.

Hasil pengukuran tegangan fasa ke fasa dan hasil perhitungan tegangan fasa ke fasa rata-rata dengan menggunakan alat yang dibuat dan alat ukur milik PLN masing-masing pada Gambar 22, 23, 24 dan 25.

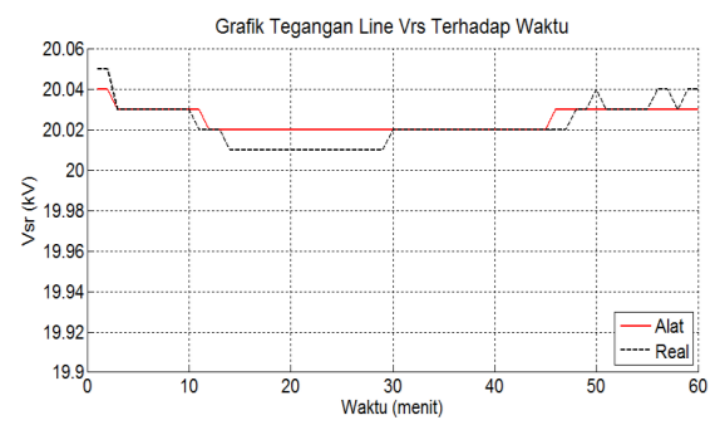

Gambar 22. Hasil Pengukuran Tegangan Line $V_{R S}$

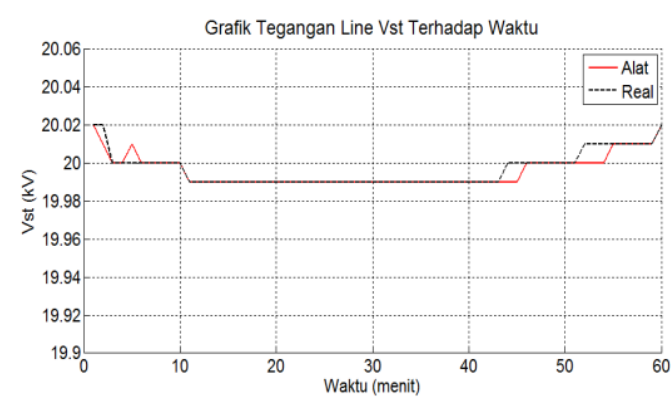

Gambar 23. Hasil Pengukuran Tegangan Line $V_{S T}$

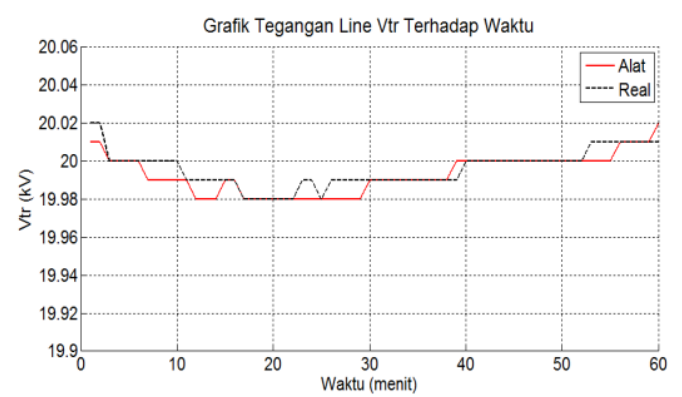

Gambar 24. Hasil Pengukuran Tegangan Line $V_{T R}$

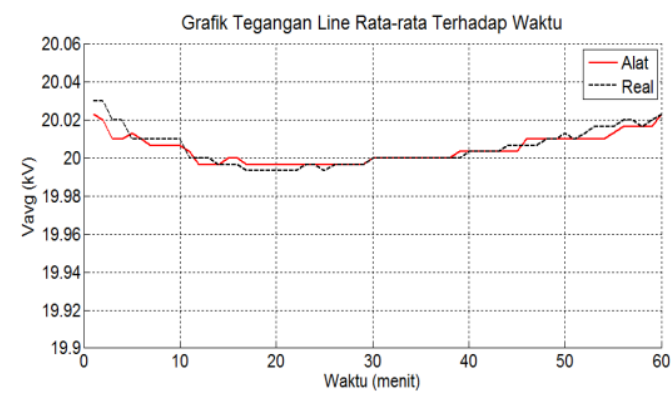

Gambar 25. Hasil Pengukuran Tegangan Line Rata-rata

Hasil perhitungan persentase ketidakseimbangan tegangan dari data yang diperoleh dengan menggunakan alat yang dibuat dan alat ukur milik PLN ditunjukkan pada Gambar 26.

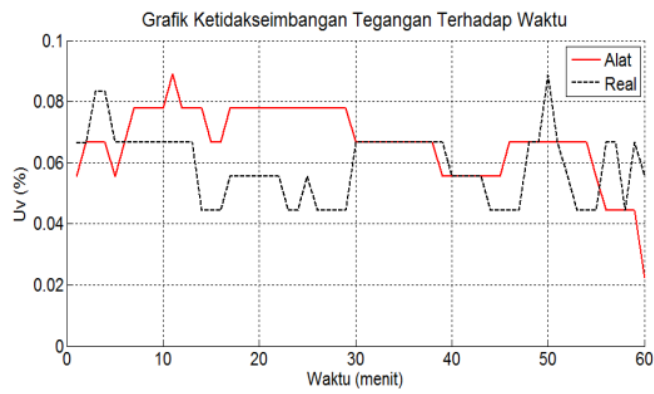

Gambar 26. Persentase Ketidakseimbangan Tegangan 
Perbedaan maksimum tegangan fasa ke fasa yang diukur dengan menggunakan alat yang dibuat dan tegangan fasa ke fasa yang diukur menggunakan alat ukur milik PLN adalah 0,01 $\mathrm{kV}$ atau sekitar $0,05 \%$. Sementara perbedaan maksimum persentase ketidakseimbangan tegangan yang dihitung oleh kedua alat ukur adalah $0,033 \%$. Sehingga selama pengujian sistem alarm tidak berbunyi dan tidak ada data yang dikirimkan ke handphone.

\section{KESIMPULAN}

Kesimpulan yang dapat diambil dari penelitian ini adalah:

1. Peralatan monitoring ketidakseimbangan beban yang dibuat dapat mengukur ketidakseimbangan beban, ketidakseimbangan tegangan dan menghitung arus netral dengan perbedaan maksimum $0,033 \%$ untuk ketidakseimbangan tegangan, $0,17 \%$ untuk ketidakseimbangan beban (arus) dan 3,96A untuk arus netral jika dibandingkan dengan nilai sebenarnya.

2. Peralatan monitoring dapat mengirimkan data ke handphone dan membunyikan sistem peringatan bila terjadi persentase ketidakseimbangan yang melebihi nilai yang sudah ditentukan.

\section{DAFTAR PUSTAKA}

[1] Salustiano, R., Neto, E., and Martinez, M., The Unbalanced Load Cost on Transformer Losses at A Distribution System, $22^{\text {nd }}$ International Conference on Electricity Distribution, pp.1-3, (2013).

[2] Motors and Generators, Nema Standards Publications No.MG-1, (1993).

[3] Wang, Y.J., and Yang, M.J., Probabilistic Modeling of Three-Phase Voltage Unbalanced Caused by Load Fluctuations, IEEE PES Winter Meeting, pp.2588-2593, (2000).

[4] von Jouanne, A., and Banerjee, B., Assessment of Voltage Unbalance, IEEE Transaction on Power Delivery, vol. 16, no.4, pp.782-790, (2015).

[5] Kolagar, A. D., Hamedani, P., and Shoulaie, A., The Effects of Transformer Connection Type on Voltage and Current Unbalance Propagation, $3^{\text {rd }}$ Power Electronics and Drive Systems
Technology Conference, pp.308-314, (2012).

[6] Kurnianto, D., Hadi, A.M. dan Wahyudi, E., Perancangan Sistem Kendali Otomatis Pada Smart Home Menggunakan Modul Arduino Uno, Jurnal Nasional Teknik Elektro, vol. 5, no.2, hal.260-270, (2016).

[7] PT. PLN (Persero) P3B SUMATERA, Pedoman $O$ dan $M$ Transformator Tenaga, (2014).

\section{Biodata Penulis}

Osea Zebua, lahir di Medan tanggal 9 Juni 1970. Menamatkan pendidikan S1 di Jurusan Teknik Elektro Universitas Sumatera Utara tahun 1995 dan pendidikan S2 di Jurusan Teknik Elektro Universitas Gadjah Mada tahun 2001.

Angga Hidson Setiawan, lahir di Bandar Lampung tanggal 15 Juni 1988. Menamatkan pendidikan S1 di Jurusan Teknik Elektro Universitas Lampung tahun 2016

Noer Soedjarwanto, lahir di Surabaya tanggal 14 November 1963. Menamatkan pendidikan S1 di Jurusan Teknik Elektro Institut Teknologi Sepuluh Nopember tahun 1991 dan pendidikan S2 di Jurusan Teknik Elektro Institut Teknologi Bandung tahun 2001.

Jemi Anggara, lahir di Muara Dua, Sumatera Selatan tanggal 25 November 1987. Menamatkan pendidikan S1 di Jurusan Teknik Elektro Universitas Lampung tahun 2016

Abdul Haris, lahir di Pematang Siantar tanggal 1 Agustus 1963. Menamatkan pendidikan S1 di Jurusan Teknik Elektro Universitas Sumatera Utara tahun 1989 dan pendidikan S2 di Jurusan Teknik Elektro Institut Teknologi Bandung tahun 1996. 